\title{
Biases at the Ballot Box: How Multiple Forms of Voter Discrimination Impede the Descriptive and Substantive Representation of Ethnic Minority Groups
}

\author{
Nicole S. Martin ${ }^{1}\left([) \cdot\right.$ Scott Blinder ${ }^{2}(1)$
}

Published online: 13 February 2020

(c) The Author(s) 2020

\begin{abstract}
Research shows that ethnic minority candidates often face an electoral penalty at the ballot box. In this study, we argue that this penalty depends on both candidate and voter characteristics, and that pro-minority policy positions incur a greater penalty than a candidate's ethnic background itself. Using a conjoint experiment embedded in a panel study of British voters, we investigate the relative contributions of candidate ethnicity, policy positions, affirmative action, and voter attitudes to this electoral penalty. We find that although Pakistani (Muslim) candidates are penalized directly for their ethnicity, black Caribbean candidates receive on average the same levels of support as white British ones. However, black Caribbean candidates suffer conditional discrimination where they are penalized if they express support for prominority policies, and all candidates are penalized for having been selected through an affirmative action initiative. We also find that some white British voters are more inclined to support a black Caribbean candidate than a white British one, all else being equal. These voters (one quarter of our sample) have cosmopolitan views on immigration, and a strong commitment to anti-prejudice norms. However, despite efforts across parties to increase the ethnic diversity of candidates for office, many voters' preferences continue to pose barriers toward descriptive and substantive representation of ethnic minority groups.
\end{abstract}

Keywords Ethnicity $\cdot$ Muslims $\cdot$ Candidates $\cdot$ Representation $\cdot$ Prejudice $\cdot$ Discrimination

Replication materials for this paper are available at https://doi.org/10.7910/DVN/SUDLEG.

Electronic supplementary material The online version of this article (https://doi.org/10.1007/s1110 9-020-09596-4) contains supplementary material, which is available to authorized users.

Nicole S. Martin

nicole.martin@manchester.ac.uk

1 Department of Politics, University of Manchester, Manchester, UK

2 Department of Political Science, University of Massachusetts, Amherst, USA 


\section{Introduction}

Political underrepresentation of ethnic minorities is a significant problem in many rich and diverse democratic nations. In Britain, as in Europe and North America, ethnic minorities are substantially underrepresented in elected office, relative to the general population (Bloemraad 2013). Underrepresentation has important negative consequences for minority groups and for societies as a whole. A lack of descriptive representation reduces responsiveness to constituents (Costa 2017), and also may reduce substantive representation, as minorities' interests and perspectives become more easily overlooked if they are underrepresented in legislatures and policy-making processes (Mansbridge 1999). Underrepresentation may also create broader problems by signaling identity-based exclusion, thereby undermining political integration, engagement, and efficacy (Merolla et al. 2013; Street 2014), and increasing political alienation (Pantoja and Segura 2003). Further, lack of representation can contribute to mass protest and even riots (Dancygier 2010).

Underrepresentation is clearly a persistent problem, but the causes remain uncertain. Some evidence suggests that one cause may be "electoral discrimination," i.e., voters' biases against minority candidates (Portmann and Stojanović 2018). This study explores this question further, examining the extent and nature of biases against minority candidates, using data collected from a representative sample of the British electorate. We leverage a new dataset and research design that allows us to test not only for direct discrimination, but also for a range of subtler forms of opposition both descriptive and substantive representation of ethnic minority groups.

Most simply, we examine the possibility of direct categorical discrimination, asking whether a candidate's ethnic minority status leads to reduced electoral support. We also examine the possibility of several subtler biases that could pose additional barriers to both descriptive and substantive representation of ethnic minority population. We ask whether voters directly challenge efforts to enhance descriptive representation through affirmative action recruitment of candidates, and likewise whether they oppose enhanced substantive representation in the form of candidates taking pro-minority positions in two policy areas. Further still, we explore the possibility of conditional discrimination: do voters impose additional penalties on pro-minority candidates if the candidate herself has a minority group identity? Finally, we also address the opposite end of the spectrum of prejudice. Here, we ask whether some white British voters are so concerned with opposing prejudice that they actually favor minority candidates over similar majority-group candidates.

We investigate these questions using a conjoint experimental design, a methodology ideally suited to testing the independent impact of multiple factors on a single decision, in this case the choice between two candidates in a hypothetical election. We find clear evidence of both direct and conditional electoral discrimination. Pakistani candidates suffer an electoral penalty on the basis of ethnicity alone. In contrast, black Caribbean candidates suffer discrimination if and only if 
they take pro-minority policy positions-these stances are generally unpopular, but are penalized even more when offered by a black Caribbean candidate. On the other hand, we also find that some voters are positively motivated by anti-prejudice principles to vote for ethnic minority candidates, even in conditions where they could opt out of choosing altogether.

Our study makes several key contributions to emerging scholarly literatures. First, we provide the most clear-cut evidence to date about the existence and degree of discrimination against ethnic minority candidates in Britain. Second, we advance beyond studies of direct discrimination by showing how voters' preferences hinder equal descriptive and substantive representation of minority populations, even for groups that do not suffer direct electoral discrimination in the aggregate. Although our study focuses on a single country, we identify mechanisms of direct and conditional discrimination that may apply more broadlyminority underrepresentation is a common issue in Western European democracies and electoral discrimination is a poorly understood potential cause. Finally, we add to the emerging literature on the increasingly important divide in British politics based on a "cosmopolitan-backwater" dimension (Jennings and Stoker 2016).

\section{Discrimination at the Ballot Box?}

Our initial question is, simply, do British voters discriminate against ethnic minority candidates at the ballot box? While it would be easy to assume that they do, the prior literature is equivocal. Analysis of observational data suggests substantial levels of discrimination. For example, Fisher et al. (2015) estimate from survey data that ethnic minority candidates-especially Muslim candidates-suffered a penalty of about four percentage points among white British voters relative to white British candidates in the 2010 general election. Stegmaier and colleagues (Stegmaier et al. 2013), using 2010 general election returns, find that incumbency advantage increased by two percentage points if the challenger was a member of a racial or ethnic minority group. Thrasher et al. (2017) find an advantage for local election "candidates whose surnames suggest a British ethnic origin," while those with non-European names had the largest disadvantage.

On the other hand, even careful observational studies are vulnerable to confounds, and experimental work finds no evidence of anti-Muslim electoral discrimination. Campbell and Cowley's (2014) survey experiment randomly varies several characteristics of hypothetical candidates for office. They do not find bias against the Muslim candidate; holding other attributes constant, a candidate named "Muhammad" fares just as well as "George." However, reanalysis of their experimental data (available from authors upon request) shows heterogeneous effects; some Labour partisans actually appear to prefer a Muslim candidate, while other groups increase rates of non-response or support for the non-Muslim candidate. Lacking more information about the identity and preferences of these respondents, we cannot explain these patterns. 


\section{Categorical Discrimination and Barriers to Descriptive Representation}

We begin with the most straightforward hypothesis, which we label the Categorical Discrimination Hypothesis. Majority-group voters may be less likely to vote for a minority candidate, all else being equal. Several theoretical traditions converge on this prediction. Categorical discrimination may reflect taste-based prejudice or "antipathy" toward other groups "based on faulty and inflexible generalization" (Allport 1954). Outright prejudice-measured as desired social distance from other groups-has declined over time in Britain, but remains fairly widespread, particularly toward Muslims, who bear the brunt of negative attitudes from other minority groups as well as from the majority ethnic group (Storm et al. 2017). A subtly different explanation is in-group favoritism, where discriminatory behavior stems from a preference for one's own group instead of or alongside prejudice against other groups (LeVine and Campbell 1972).

In the context of representation, there might be a third, related, explanation for direct discrimination in vote choice: a desire for descriptive representation among majority-ethnicity voters. Descriptive representation is usually discussed as having value for underrepresented groups such as women and minorities (Mansbridge 1999), but some evidence shows that members of majority groups have even stronger preferences for in-group representatives (Gay 2002). In the US case, a substantial proportion of white voters seem to fear the consequences of descriptive representation of minority groups (Parker and Barreto 2014), whilst some working class white Americans and Britons explicitly characterize themselves as minority group members and believe that they face discrimination and lack representation (Gest 2016). For such individuals, the racial or ethnic identity of their representatives may be important symbolically (Tate 2001).

All of these underlying mechanisms lead to one essential result: a decreased likelihood of voting for a candidate simply due to their membership in an ethnic minority category. This discrimination may stem from prejudice, in-group trust and favoritism, or beliefs about the value of descriptive representation (in a society in which race and ethnicity are salient identities), or some combination thereof, but in our context these are observationally equivalent, and therefore can be combined into a single hypothesis predicting categorical discrimination, or, again, simply that ethnic minority candidates will draw less support than otherwise identical white British candidates.

\section{Substantive Representation and Conditional Ethnic Penalties}

Although most prior work on electoral discrimination in Britain and elsewhere looks for categorical discrimination, voters' biases and preferences can contribute to the underrepresentation of ethnic minority groups in other ways. We suggest that ethnic minority candidates may face several forms of conditional discrimination, in which voters' discrimination depends on the candidates' policy positions or other characteristics. 
First, we propose the Substantive Representation Hypothesis: majority-group voters may oppose the substantive representation of minority interests by any candidate, regardless of that candidate's own ethnicity. White voters might resist substantive representation of minority voters' preferences in line with divergent issue opinions. For example, data from the Ethnic Minority British Election Study and the main British Election Study show marked differences in support for affirmative action between ethnic minority and white British groups: $70 \%$ of ethnic minority respondents favored improving opportunities for black and Asian people, compared to $20 \%$ of white British (Heath et al. 2013). On immigration, 50\% of minorities opposed sending most asylum seekers home immediately, compared to $39 \%$ of the white British —not as stark a difference, but still a significant one. If candidates cannot succeed when promoting policies that are preferred by more ethnic minority voters, there may be a deficit of substantive representation regardless of whether minority candidates are elected. The phenomenon of symbolic inclusion-where minority candidates are selected primarily for their appeal to white voters as a symbol of liberalism and not for their strong ties to minority voters and interests_-illustrates parties' awareness of this dilemma (Dancygier 2017, p. 28).

The Substantive Representation Hypothesis does not entail direct disadvantages for ethnic minority candidates. In practice, however, opposition to substantive representation would likely disadvantage such candidates, as empirically they are more likely to seek to represent minority constituents' substantive interests (Sobolewska et al. 2018). For example, ethnic minority MPs are more likely to ask official Parliamentary Questions about minority rights and about immigration (Saalfeld and Bischof 2013). Thus, substantive representation may well go hand in hand with descriptive representation.

In addition, we suggest a potential interaction effect, in which minority candidates may pay a larger price at the ballot box for taking pro-minority policy positions than white candidates pay for holding the same view. This possibility-the Conditional Ethnic Penalty Hypothesis - draws on a "group-centric" view of voters (e.g., Huddy 2018). Candidates' issue views may convey information not only about the policies they pursue but also about group loyalties, i.e., whose interests they will tend to represent if elected. As noted above, white voters often fear minority leaders will prioritize minority interests at their expense (Fulton and Gershon 2018). This perception of minority candidates is particularly difficult to dispel, even with contrary information about candidate ideology (Karl et al. 2016). If minority candidates promise to promote minority groups' interests, white voters may assess a conditional ethnic penalty above and beyond what a white candidate would face for taking an unpopular policy position.

\section{Methods/Data}

\section{Case Selection: Britain}

We test these three major hypotheses, along with several extensions described below, in the context of Great Britain, and more specifically in the run up to the 
2017 general election, which was called three years early and initially centered the Brexit divide (Cowley and Kavanagh 2018).

Britain is well-established as a multi-ethnic democracy, with ethnic minorities comprising $10 \%$ of the electorate and $10 \%$ of the House of Commons. ${ }^{1}$ In common with other former European imperial powers, the predominant form of migration to post-war Britain originated from colonial ties. The largest ethnic minority groups in the 2011 Census were people of Indian, Pakistani, black African, black Caribbean and Bangladeshi ethnicity, many of whom were born in the UK (as much as $60 \%$, in the case of those identifying as black Caribbean). More recent migration patterns have brought large numbers of immigrants from Central and Eastern European EU member states; in 2015 the number of Polish-born residents in the UK exceeded the Indian-born to become the largest country of origin for British immigrants (Rienzo and Vargas-Silva 2018). Adding to the diversity of the electorate, the UK is unusual in granting full voting rights to immigrants who are non-citizens if they are citizens of a Commonwealth country instead, so many minority groups have high levels of eligibility and participation in elections, with the exception of EU immigrants and some groups of black Africans without Commonwealth citizenship.

Our study focuses on potential discrimination against candidates of black Caribbean and Pakistani ethnicity, both prominent ethnic minority groups with long and distinctive histories in Britain, and with high levels of political activity. Initially, migrants from the Caribbean were directly recruited by the Ministry of Labour for jobs in professions in the healthcare and transport sectors, whilst Pakistani migration addressed labour shortages in industries including textiles, engineering and steel. Later, family reunification policies meant that migration continued despite curbs on labour migration (Messina 2007). War between then East and West Pakistan-now Bangladesh and Pakistan - also played a role. In recent years, migration from Pakistan has continued-in particular through student migration (Luthra and Platt 2016), but that directly from the Caribbean has slowed. Moreover, British Pakistanis are predominantly Muslim, and thus more distinct from the majority population on religious lines. We therefore expect that stereotypes or antipathy towards one of these groups may not apply to others.

In particular, we expect Pakistani candidates will receive higher levels of opposition than other minority groups. This is primarily due to high observed levels of Islamophobia (Storm et al. 2017), likely to be directed at this large, salient and overwhelmingly Muslim ethnic minority group. ${ }^{2}$ Indeed, the far right in the UK adopted Islamophobia as a more acceptable form of ethnocentrism than biological racism (Goodwin 2011). Recent survey evidence suggests lower (though still considerable) levels of outright prejudice toward black people in Britain than toward Muslims, with $44 \%$ saying that they would personally mind if a close relative were to marry a

\footnotetext{
165 MPs from ethnic minority backgrounds were elected in the 2019 general election of 650 MPs in total, in line with the proportion of ethnic minorities in the electorate. At the time of fieldwork however this proportion was only $6 \%(42)$.

${ }^{2}$ Pakistani ethnicity is especially salient in a British context because a truncated form of the term is a racial slur frequently used against people of South Asian ethnicity.
} 
person of Muslim origin, compared to $22 \%$ who would mind if the person were of black or West Indian (an older term for Caribbean) origin (Kelley et al. 2017). Parallel research in the United States suggests that specific prejudice against Muslims as a group is strongly correlated with ethnocentrism and negative attitudes towards other ethnic and racial minorities (Sides and Gross 2013; Kalkan et al. 2009). This heightened and specific anti-Muslim hostility is consistent with research on Britain suggesting that discrimination, lack of integration, and potential for political conflict remain higher with respect to British Muslims than with respect to other minority groups (Modood 2005). In particular, black Caribbeans as a group enjoy greater social integration (Maxwell 2010) and fewer discriminatory attitudes (Ford 2011).

Aside from its status as a multi-ethnic democracy, Britain provides a useful setting for this study for two main reasons: (i) ethnic minority candidates stand for all parties (Sobolewska 2013), and (ii) observational evidence suggests electoral discrimination in British elections (Stegmaier et al. 2013; Thrasher et al. 2017; Fisher et al. 2015).

Unlike the US, race/ethnicity of political candidates can be disentangled easily from party membership. Although the Labour party took the lead in fielding minority candidates (electing the first post-war ethnic minority MPs in 1987), the number of ethnic minority MPs for the Conservative party has increased sharply since 2005, especially in safer seats with largely white electorates (Sobolewska 2013). This means that many Conservative minority candidates rely strongly on white voters for their election. The Labour party also selects more minority candidates in safe seats, but these safe seats have higher proportions of ethnic minority electors (Sobolewska 2013). Notably, this pattern of running minority candidates in safer seats may suggest that both major parties anticipate some electoral discrimination, and select seats with lower marginality for minority candidates to minimize the costs of this discrimination as much as possible. This is feasible as central bodies in both parties exercise a degree of control over shortlists, especially in the shortened timescale of the 2017 general election (Moisi et al. 2017). However, it also makes it more difficult to estimate the impact of electoral discrimination from observational data, since those data arise in part from a strategic process of candidate selection which itself is affected by beliefs about voter biases. Thus, an experimental test is needed to determine whether observational evidence of electoral discrimination is substantiated, and to explore whether any discrimination we find is focused on descriptive or substantive representation.

\section{Study Design}

Our data come from a conjoint experiment embedded in wave 11 of the British Election Study Internet Panel (BESIP) with 7903 respondents (Fieldhouse et al. 2017). The fieldwork took place between April 24 and May 3, 2017, before the 2017 general election, which was held on June 8 after being called on April 18. The BESIP recruits a representative sample of the British population (excludes Northern Ireland) from the YouGov online panel, using targeted quota sampling. All respondents are eligible to vote in at least one type of election (as determined by citizenship 
and age). Surveys are completed in a web browser. In wave 11, the experiment was fielded to a random subsample of the overall survey.

In the conjoint experiment, respondents were asked to choose between two hypothetical candidates who varied randomly on a series of characteristics, including party, ethnicity, ${ }^{3}$ gender, policy position on migration and refugees, priorities for law enforcement, and their route into politics. Each candidate was described in a vignette with the following structure, where italicized words inside square brackets were varied randomly:

[Name] is a candidate in your area from the [Conservative party/Labour party], who comes from a [white British/Pakistani/black Caribbean] background. [He/She] is in favour of [letting skilled migrants enter the country to fill jobs in sectors with skill shortages/accepting more refugees who are fleeing war or persecution/strongly limiting migration to the $U K]$. [He/She $]$ thinks that [race equality laws/laws against anti-social behaviour should be more strictly enforced, with greater penalties for those found guilty of harassment and discrimination/disturbing the public order]. ${ }^{4}$ [Name] became a candidate after [being included on a list of candidates from under-represented backgrounds/ getting involved in the political party].

The two vignettes were presented on the same page. Respondents were then asked which candidate they preferred: "Which of these candidates would you rather have as your MP?".

By varying all of the candidate characteristics randomly, the conjoint design allows us to estimate the effects of any one of them, independently of the others and without bias (Hainmueller et al. 2014). This makes it an ideal tool to test simultaneously for the wide array of hypothesized direct and conditional forms of discrimination. For example, Abrajano et al. (2018) used a conjoint design to study categorical discrimination in the US electoral context, finding substantial effects of ethnic (Latino) names on candidate preference. Table 1 below summarizes the experimental design, highlighting hypothesized sources of minority candidate disadvantage.

First, varying ethnicity allows us to test for categorical discrimination. Note that we vary the candidates' names to accompany the ethnicity (and candidate gender) manipulations, as naming traditions vary across ethnic groups. White British candidates were named Oliver and Emily, Pakistani candidates were named Omar and

\footnotetext{
3 Readers unfamiliar with UK might find it helpful to know that White British is a category for ethnicity in the UK Census, alongside Caribbean and Pakistani. Pakistani as a category falls under Asian/Asian British, and Caribbean falls under the broader category Black/Black British. This terminology is commonplace, and we believe that participants in the UK would not think that a candidate from a Pakistani or black Caribbean background lacked citizenship or residence rights. White British is often used to draw a difference between white people who are native to the UK, those who are immigrants from other European countries, who the Census classifies as White Other, white people who are from Ireland, who the Census classifies as White Irish, and white people who are from a Gypsy or Irish Traveller background.

4 The wording within this set of brackets represents one randomly-assigned variable, even though there are two sets of italicized words. The "race equality" treatment used "race equality laws" and "harassment and discrimination;" the "anti-social behaviour" condition used "laws against anti-social behavior" with "disturbing the public order.".
} 
Table 1 Conjoint design, with hypotheses

\begin{tabular}{lll}
\hline Candidate attribute & Options & Hypothesized interactions \\
\hline Ethnicity & $\begin{array}{l}\text { White British } \\
\text { Black Caribbean } \\
\text { Pakistani }\end{array}$ & $\begin{array}{l}\text { Minority } \times \text { IMCP } \\
\text { Minority } \times \text { neither option }\end{array}$ \\
Entry into politics & $\begin{array}{l}\text { List of underrepresented OR } \\
\text { became involved in party } \\
\text { Skilled immigration } \\
\text { Immigration policy }\end{array}$ & List of underrepresented $\times$ minority \\
& $\begin{array}{l}\text { Strictly limit } \\
\text { Enforce race equality law OR } \\
\text { anti-social behavior law } \\
\text { Law enforcement }\end{array}$ & $\begin{array}{l}\text { Skilled immigration } \times \text { minority } \\
\text { Pro-refugee } \times \text { minority }\end{array}$ \\
Gender & $\begin{array}{l}\text { Pro-equality } \times \text { minority } \\
\text { Party }\end{array}$ & $\begin{array}{l}\text { Female } \times \text { minority } \\
\text { Conservative candidate } \times \text { minority } \\
\text { Conservative voter } \times \text { minority }\end{array}$ \\
\hline
\end{tabular}

Boldface shows factors with hypothesized negative impact on candidate vote share. Boldface underlined indicates that we expect Pakistani candidates to have a stronger electoral penalty than black Caribbean candidates

Fatima, and black Caribbean candidates were named Joshua and Gabrielle. In addition, in case a given respondent was randomly assigned two candidates of the same ethnicity and gender, we assigned the second name from an alternate list that also are common for each ethnicity/gender combination: George, Sarah, Mohammad, Maryam, Daniel, and Kim.

Next, to test the Substantive Representation Hypothesis, we vary candidates' policy positions. The design allows us to look for the effects of policy positions independent of candidate ethnicity to test the Substantive Representation Hypothesis. We include two policy areas, immigration and anti-discrimination law, which are contentious differences in issue positions between majority and minority group members in Britain in recent years. Immigration in particular has been a highly salient policy issue in Britain since the early 2000s (Blinder and Richards 2019) and was central in the political dissatisfaction that lead to the Brexit vote (Evans and Menon 2017), while anti-discrimination law is a much stronger policy priority for ethnic minorities than white British voters (Heath et al. 2013).

The inclusion of these issues also allows us to test for the conditional discrimination predicted by the Conditional Ethnic Penalty Hypothesis. We estimate interaction effects between candidate ethnicity and policy positions to test for this possibility. The conjoint design also permits a number of additional possibilities, discussed further below.

\section{Analysis and Population of Interest}

The data were unstacked following Hainmueller et al. (2014), so that each row corresponds to one candidate, their characteristics, and whether the respondent said they would vote for them or not. Each row in the data set is a candidate + characteristics combination, and the model is of the effect of these characteristics on their selection, 
independent of their opponent. Thus, each participant provided two cases- the choice to vote or not vote for each of the two candidates presented to them in the set of vignettes. This means that the 7,903 participants in the study provide double that number of cases for analysis $(n=15,806)$.

We use logistic regression to estimate the Average Marginal Component Effect (AMCE) for each of the candidate attributes varied in the design. We also estimate interaction effects between multiple candidate attributes (Average Component Interaction Effects, or ACIE) and between attributes and respondent characteristics (conditional AMCE, where AMCE is conditional on the value of a given respondent characteristic).

Since our population of interest is the British electorate, we analyze the results from all respondents, rather than selecting only white British respondents. This is more comparable with studies relying on election returns, and acknowledges that black Caribbean or Pakistani candidates might face prejudice from voters with other ethnic minority or white non-British backgrounds. Where appropriate we conduct a robustness check of limiting the analysis to those identified as white British; this is used to distinguish support for minority candidates from non-minority voters due to commitment to anti-prejudice norms, and support for co-ethnic candidates by minority voters.

\section{Results $^{5}$}

We begin by examining the main effects of candidate attributes on vote choice. We find, first of all, that support for the Categorical Discrimination Hypothesis depends on candidate ethnicity. We find clear evidence of categorical discrimination against the hypothetical Pakistani candidate, as we can see by examining the top three rows of Fig. 1. These rows show the marginal effect of Pakistani and black Caribbean candidate ethnicity relative to a white British candidate baseline. Lines indicate $95 \%$ confidence intervals around these estimated effects. The AMCE of Pakistani ethnicity is $-0.06(\mathrm{p}<0.001)$, for an estimated six percentage point disadvantage, relative to the white British candidate.

On the other hand, we do not find evidence of categorical discrimination against the black Caribbean candidate, with an AMCE that is indistinguishable from zero $(b=-0.003, p=0.74)$. As we will show below, black Caribbean candidates suffer subtler forms of discrimination, but our results do not show a straightforward ethnic penalty. Thus, our results are consistent with previous observational evidence that only Muslim candidates suffered an ethnic penalty in the 2010 general election (Fisher et al. 2015), and with work on the particular potency of Islamophobia, over and above general ethnocentrism, in British political and social attitudes (Storm et al. 2017).

\footnotetext{
5 We focus on presenting the most important results in the text and/or visual form. Full tables can be found in the Supplementary Information.
} 


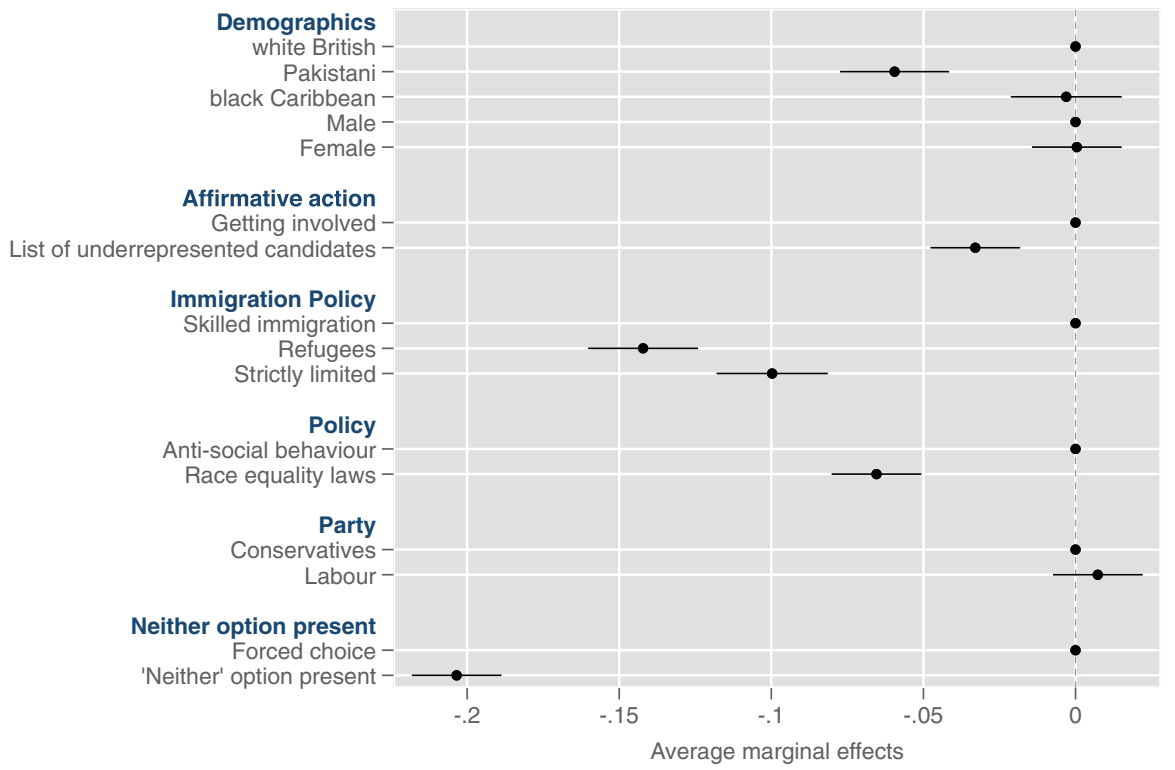

Fig. 1 Main effects of candidate characteristics on vote choice

Meanwhile, we find strong support for the Substantive Representation Hypothesis. Candidates were penalized for taking positions on both law enforcement and migration policy that could be seen as providing substantive representation of minority groups' interests or policy preferences. Candidates who prioritized enforcing anti-social behavior laws were more popular than the pro-minority position of prioritizing enforcement of racial equality laws. This is seen in the positive effect of "anti-social behavior" relative to the "race equality laws" baseline under the heading "Policy".

Voters also strongly penalized candidates who took the most liberal position on immigration policy, which was offering to accept more refugees fleeing war or persecution. This effect was the largest in magnitude of any candidate characteristic in the experiment, as can be seen by comparing marginal effect sizes in Fig. 1. The fourteen percentage point penalty (relative to the moderate immigration position) far outdistanced the largest penalties for candidate ethnicity (six points), affirmative action background (three points), and advocacy for enforcing race equality laws (seven points). Note that these were average effects for candidates of all three ethnic groups tested, including white British.

Since ethnic minorities in Britain are more supportive of immigration and refugees, this result exemplifies the difficulty of substantive representation for minority group interests in a majoritarian system. It is important to note, however, that the immigration policy position associated with the greatest electoral performance was not the most anti-immigration position. Rather, support for skilled immigration in shortage sectors outperformed the most restrictive option, which was "strongly limiting migration to the UK." 
The size of the effects for immigration policy compared to candidate ethnicity and other characteristics underlines the salience of immigration to candidate and party choice at the time of the 2017 election. It may be somewhat reassuring that policy positions have a stronger effect on hypothetical vote choice than candidate ethnicity when separated by experimental control. However, as we shall see below, the importance of policy positions is not entirely good news for minority candidates' electoral prospects.

\section{Conditional Ethnic Penalties: Black Caribbean Candidates Punished for Pro-minority Positions}

As discussed above, discrimination at the ballot box may be subtler than simple categorical discrimination. We examine the effects of interactions between candidate ethnicity and other candidate attributes, by estimating a logistic regression model that included all candidate attributes, plus interactions between ethnicity and each of the other candidate attributes. This allows us to test our Conditional Ethnic Penalty Hypothesis.

The results support the hypothesis: ethnic minority candidates are in fact penalized more than white candidates for offering substantive representation of minority group interests. Voters punished all candidates who took these positions, but the penalties tended to be larger for ethnic minority candidates. In the case of immigration policy, black Caribbean candidates supporting more generosity toward refugees rather than a policy of skilled immigration suffered an eighteen point penalty, compared to twelve for white British and thirteen for Pakistani candidates, as illustrated in Fig. 2. Here, the conditional ethnic penalty seemed focused on black Caribbean candidates, although it is important to keep in mind that Pakistani candidates begin from a lower baseline of support, so this difference may simply even things out between these groups.

Meanwhile, voters punished both ethnic minority candidates more than they punished the white British candidate for supporting greater enforcement of race equality laws. The coefficient on the interaction term for Pakistani candidates is only significant at the $10 \%$ level $(\mathrm{p}=0.09)$, but it is very similar to that for the black Caribbean candidate, implying a seven point penalty for Pakistani candidates and a similar eight point penalty for black Caribbean candidates if they support greater enforcement of racial equality laws, compared with just a four point penalty for a similar white British candidate.

Taken together, then, our main results support all three hypotheses about electoral discrimination. We found evidence of categorical discrimination, although only against Pakistani candidates. However, we found that voters penalized substantive representation of pro-minority positions in all candidates, confirming the Substantive Representation Hypothesis. Further, we found Conditional Ethnic Penalties against black Caribbean candidates in both policy areas, and against Pakistani candidates in the case of policy towards anti-discrimination law enforcement. These differences vary in substantive size, but some are quite large, and all of them are significant enough to make a difference in a close election. 

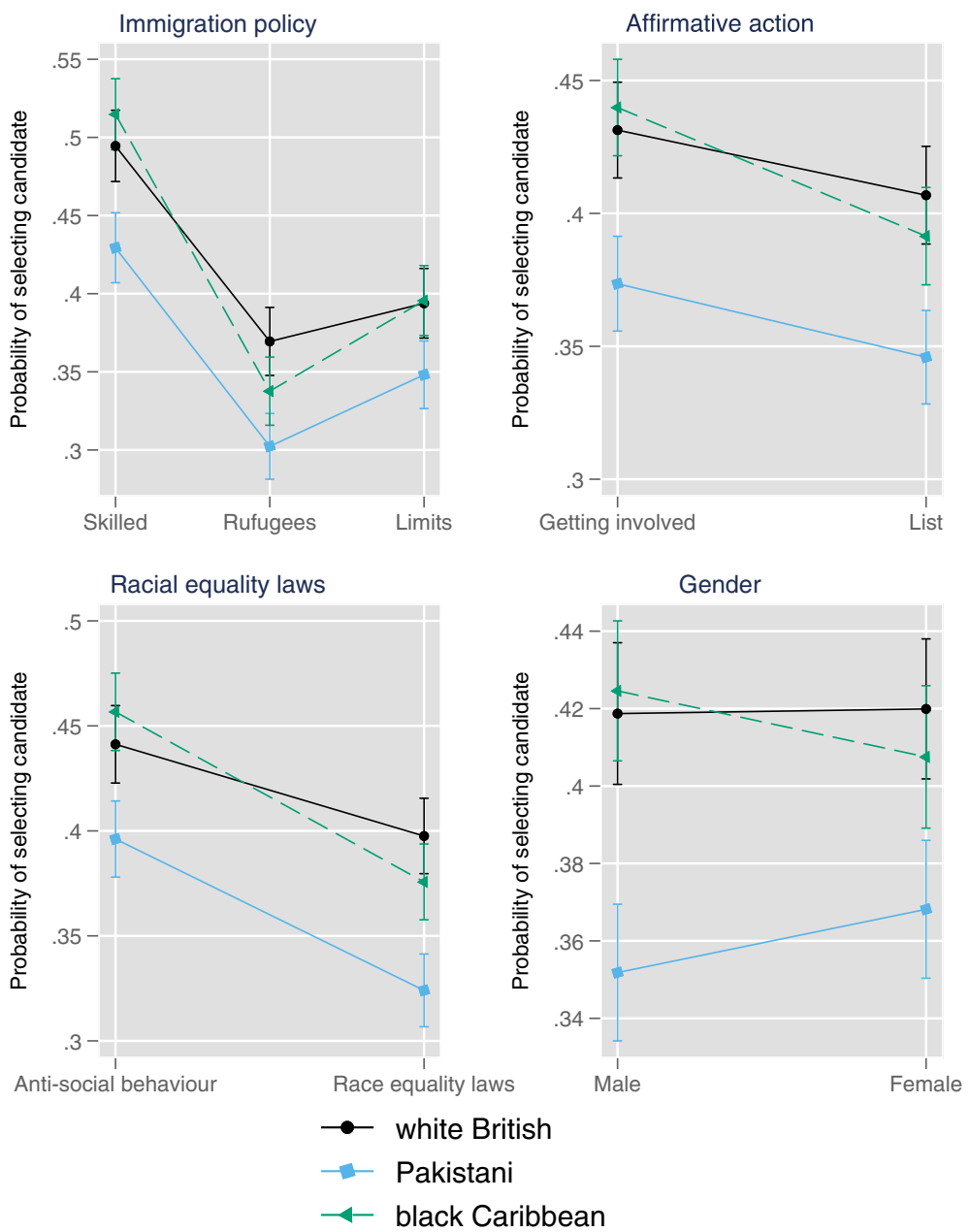

Fig. 2 Effects of candidate characteristics interacted with candidate ethnicity on vote choice

\section{Extensions}

In addition to our main hypotheses, our conjoint design allows us to test a number of additional hypotheses. These are fourfold; (i) opposition to positive action recruitment practices, particularly when used to increase descriptive representation of ethnic minority groups, (ii) further conditional ethnic penalties according to gender and party, (iii) differential responses to candidate ethnicity depending on political and normative commitments, and (iv) greater support for minority candidates among minority voters. 


\section{Attitudes to Affirmative Action}

Affirmative action, implemented in the construction of shortlists for potential candidates, is a key means toward increasing descriptive representation in Britain. In fact, because local party members play a significant role in candidate selection, the main policy lever for national parties in these efforts is their control over the shortlists from which local party members select candidates for office. For example, Labour instituted All Women Shortlists to this effect, whilst the Conservative party used the non-binding but still reasonably effective "A-list" of preferred candidates to increase gender balance, ethnic diversity and widen the range of backgrounds represented by Conservative parliamentary candidates (Dommett 2015). However, although these methods generated more diverse sets of candidates, little is known about voters' reactions to them. To address this, we varied whether the candidate was described as 'being included on a list of candidates from under-represented backgrounds', or the more neutral-sounding 'getting involved in the political party'. Returning to Fig. 1, we can see that participants penalized direct efforts at descriptive representation of underrepresented groups, beyond the impact of categorical discrimination; candidates who had "got involved" were 4 points more preferred than ones who had benefitted from positive action. This suggests an aversion to existing efforts to achieve descriptive representation.

\section{Further Conditional Ethnic Penalties}

We also vary gender and party affiliation of candidates to test for conditional discrimination along these dimensions-in particular conditional ethnic penalties for ethnic minority women (Crenshaw 1989), and ethnic minority candidates from the Conservative party (Besco 2018). Table 1 above summarizes the variation included in the conjoint design.

Contrary to our expectations, we did not find evidence for conditional ethnic penalties for non-policy candidate characteristics. Notably, there was no significant conditional ethnic penalty for candidates who became involved through affirmative action recruitment. There were trends in that direction, particularly for black Caribbean candidates, but effects were not statistically significant $(b=-0.11, p=0.19)$. We also did not find evidence for a double penalty for female minority candidates, as there was no significant interaction between ethnicity and gender.

A different potential conditional ethnic penalty is the role of political party. As noted above, ethnic minority candidates regularly stand for election in both the Labour and Conservative parties. Figure 3 plots the marginal effects of candidate ethnicity interacted first with candidate party, and secondly, respondent's vote intention. Candidate party does not matter; minority candidates faced no additional penalty as a result of standing for the Conservative party. The voter's party, by contrast, does matter. The penalty for Pakistani candidates (compared to white British ones) is reduced from nine percentage points among Conservative voters to three points among Labour voters. There is also a small penalty of three points for black Caribbean candidates among Conservative voters (against white British candidates). This 


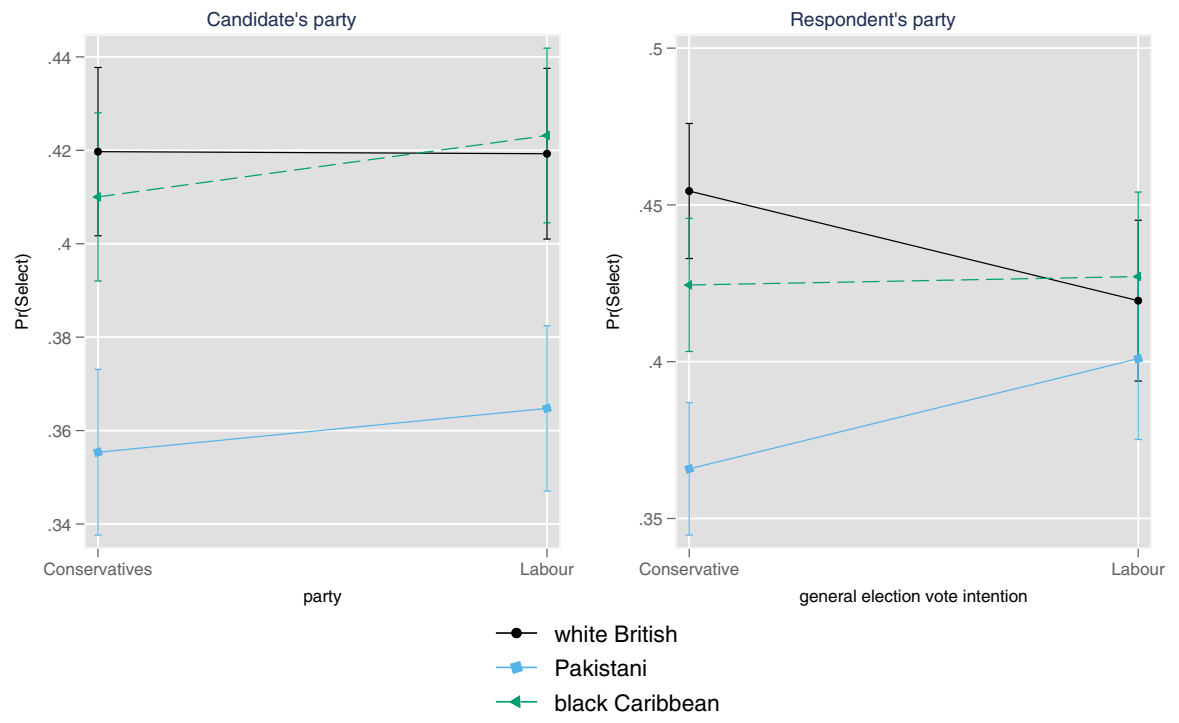

Fig. 3 Marginal effects of candidate ethnicity by (i) candidate party and (ii) respondent's vote intention

implies that the party of ethnic minority candidates is important solely because of the relative levels of prejudice-or, as we will see below, relative support for antiprejudice norms - among voters for different parties. Simply put, minority candidates are likely to fare better as Labour candidates because Labour voters are less likely to discriminate, not because there is a particular opposition to minority candidates who run as Conservatives.

\section{Internal Motivation to Control Prejudice}

In another extension of the main study, we explored the extent to which voters motivated by anti-racist social norms might, in some circumstances, actually prefer an ethnic minority candidate to an otherwise similar majority ethnic candidate. To this end, after the vote choice question, respondents were asked two items from a scale to measure their Internal Motivation to Control Prejudice, validated previously in the European context (Blinder et al. 2013; Ivarsflaten et al. 2010). Respondents were asked how much they agree or disagree with the following statements; "I attempt to act in non-prejudiced ways towards immigrants because it is personally important to me," and "I aim to be non-prejudiced towards immigrants due to my own convictions." Response options were on a five point Likert scale, with a "don't know" option. These questions were asked subsequently so that respondents would not be primed to think about social norms against prejudice while making their choices in the candidate experiment.

To test whether Internal Motivation to Control Prejudice (IMCP) moderates the effect of candidate ethnicity, we calculated the marginal effects from a logistic 


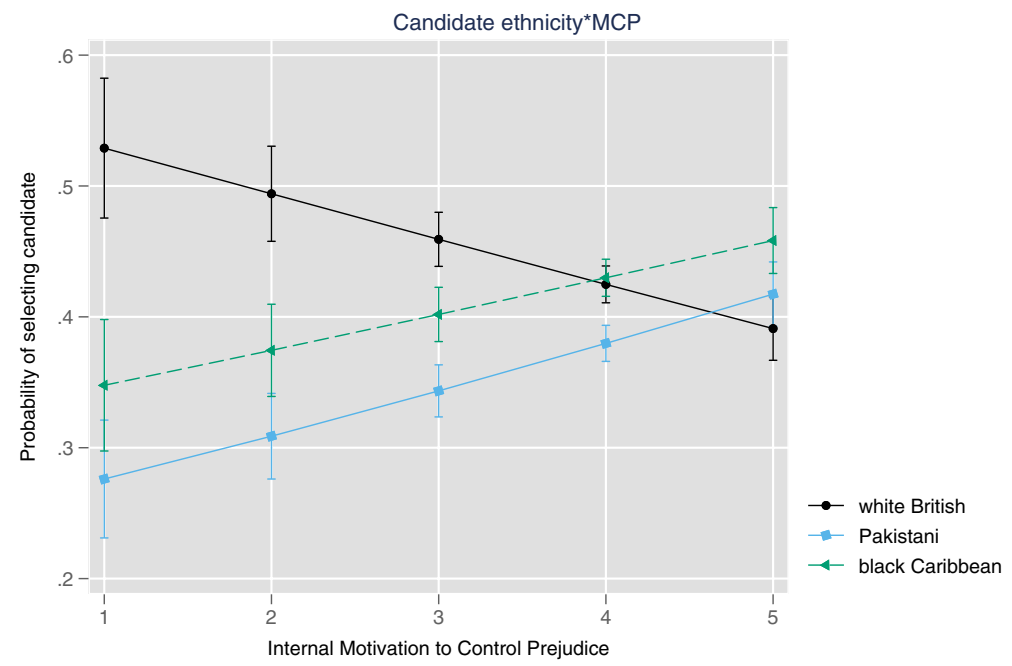

Fig. 4 Marginal effects of candidate ethnicity at different levels of internal motivation to control prejudice

regression model where candidate ethnicity is interacted with respondents' IMCP score, displayed in Fig. 4. We control for a number of other relevant attitudes ${ }^{6}$ to try to avoid concerns that this only identifies ethnocentrism or a lack of prejudice itself. Our expectations are confirmed; respondents with low levels of IMCP are the most likely to vote for white British candidates. Conversely, for both black Caribbean and Pakistani candidates, it is individuals with higher levels of IMCP - that is, a greater commitment to anti-prejudice norms - who are most likely to vote for them.

Furthermore, looking only at respondents in the top quartile of IMCP, we find support for the idea that some British voters are positively motivated to vote for ethnic minority candidates, all else equal. Among this top quartile, we find a positive effect of black Caribbean candidate ethnicity on candidate choice and a positive trend but no statistically significant impact of Pakistani candidate ethnicity. For black Caribbean candidates the marginal effect is a boost of eight points (compared to white British candidates); for Pakistani candidates the difference is four points. This result is robust to removing ethnic minority voters from the sample, eliminating the possibility that positive voting for minority candidates only occurs among minority voters.

To alleviate concerns that these results may have been affected by the positioning of our IMCP items after the conjoint experiment in which our dependent variable was measured (Montgomery et al. 2018), we replicated these results using an

\footnotetext{
${ }^{6}$ These are the extent to which respondents think that (a) immigrants undermine the welfare state, (b) immigration is bad for the economy, (c) immigration undermines cultural life, (d) the level of immigration should be reduced, (e) feeling thermometer scores towards blacks and Asians, and (f) respondent ethnicity.
} 
alternative moderating variable with similar properties. BESIP respondents were also asked in the same wave but before this experiment if they think that "immigration undermines or enriches Britain's cultural life." Respondents at the high end of this scale place a positive value on diversity of national and cultural backgrounds, similar to those on the high end of the IMCP scale. Indeed, the immigration item may tap even more directly into the emerging values divide along the cosmopolitanism dimension (Jennings and Stoker 2016). Among white British respondents who agreed most strongly that immigration enriches our cultural life, we find similar results to the top quartile of the IMCP scale: a statistically significant positive coefficient for black Caribbean candidate ethnicity (5 point advantage), and a positive but not statistically significant coefficient for Pakistani candidate ethnicity (4 points). This echoes the analysis of Kalkan et al. (2018), who find in a vignette experiment that Americans with positive views of cultural outgroups are more likely to support a Muslim candidate than a baseline candidate of non-specified religion or ethnicity.

We also sought to ensure that these results were not simply an artifact of social desirability bias. Perhaps high IMCP individuals are not truly motivated to see improved representation of ethnic minorities, but rather are expressing views that they believe conform to normative standards of the broader society (or of the survey researchers). Fortunately, earlier waves of the BESIP included the Brief Social Desirability Scale (BSDS) a widely-used and validated measure of social desirability bias (Haghighat 2007). Due to attrition, this measure is non-missing for $51 \%$ of our participants. First, we use this measure to confirm the distinction between IMCP and social desirability. We find a small positive correlation between IMCP and BSDS $(r=0.10)$. Second, we repeat the logistic regression analysis controlling for the interaction between BSDS scores and candidate ethnicity, and find that it does not change the result that higher IMCP predicts greater support for minority candidates, and lower for white British candidates. These results confirm that findings for IMCP are not a mere artifact of social desirability response bias, in accord with prior validation studies (Ivarsflaten et al. 2010; Plant and Devine 1998).

\section{Electoral Support for Ethnic Minority Candidates Among Minority Voters}

Given the large sample size of this experiment, it is also possible investigate whether ethnic minority participants preferred ethnic minority candidates. The observational literature on the UK suggests that this occurs only among Pakistani voters, but finds little evidence for other ethnic groups (Fisher et al. 2015; Martin 2015). To test whether ethnic minority voters prefer minority candidates, we conduct two analyses. Firstly, we test whether any ethnic minority candidate (i.e., black Caribbean and Pakistani) is preferred compared to a candidate identified as white British among all ethnic minority voters. We find that among the 720 observations from 360 respondents who belong to an ethnic minority group, any ethnic minority candidate has a 5 point advantage over a white British candidate, but this difference is not statistically significant $(\mathrm{p}=0.14)$. Secondly, we test the effects of candidate ethnicity among (i) respondents who are one of Pakistani or Bangladeshi ethnicity, or report that they are Muslim, and (ii) black Caribbean, black African or mixed black ethnicity, in order to identify any co-ethnic preference. 
Among the 136 observations from 68 respondents who are Pakistani, Bangladeshi and/ or Muslim, the Pakistani candidate has a 14 point advantage over a white British candidate, and the black Caribbean candidate a 9 point advantage. Meanwhile, black voters give a 16 point advantage to a black Caribbean candidate relative to the white British one, and a 4 point penalty to the Pakistani candidate. However, we are cautious to draw too many conclusions from this result as this is based on 166 observations from 83 respondents. Although the coefficient for black Caribbean candidate ethnicity is significantly different from the Pakistani coefficient, neither of these coefficients are significantly different from the white British coefficient $(\mathrm{p}=0.64$ for Pakistani candidate ethnicity and 0.09 for black Caribbean). Moreover, research has shown the unsuitability of this particular online panel for research on minority voter preferences (Martin 2019).

\section{The 'Neither' Experiment}

In addition to the main conjoint design, we added an additional experiment within the vote choice question. The response options on this question were randomly varied to include or not include an explicit option to choose 'neither' candidate. This tested whether forcing a choice between candidates produces more prejudiced responses. If true, this would explain the null finding of voter prejudice against a Muslim candidate in the experiment by Campbell and Cowley (2014) which did include a 'neither' option, thus reconciling the inconsistencies between experimental and observational studies in the prior literature.

Contrary to our expectations however, the neither option made only a small and statistically non-significant difference in the likelihood that respondents selected an ethnic minority candidate. In the forced choice condition, $35 \%$ chose a white British candidate, while $30 \%$ chose a Pakistani candidate. With the neither option, these percentages change to $22 \%$ and $18 \%$, respectively. Respondents were also no more likely to select neither candidate when faced with an ethnic minority candidate. Therefore, we have not been able to resolve the paradox in the UK literature between Campbell and Cowley's (2014) experimental null finding and observational studies of ethnic penalties (Stegmaier et al. 2013; Fisher et al. 2015; Thrasher et al. 2017).

\section{Discussion}

We have shown that electoral discrimination by British voters poses several distinct obstacles to the election of ethnic minority candidates, and therefore to rectifying the problem of underrepresentation. Electoral discrimination is a disadvantage in and of itself, and also may provide an incentive for strategic elites to act as gatekeepers against rising minority candidates rather than making positive efforts to recruit them (Dancygier et al. 2015). Ethnic minority candidates face several distinct types of penalties at the ballot box, especially if they seek to represent minority group interests substantively.

Our results suggest barriers to both descriptive and substantive representation, with different emphases for the two different groups included in our study as 
candidates. In the aggregate, categorical discrimination reduced support for hypothetical Pakistani candidates but not for black Caribbean candidates. Future work might explore responses to candidates from other ethnic and religious minority groups, in Britain and in other European countries as well, to see whether categorical discrimination is the exception or the rule, and whether it is systematically more likely for Muslim minorities than for Europe's other minority groups.

A second finding suggests an additional barrier to descriptive representation: heightened opposition to candidates who were recruited through affirmative action efforts to identify candidates from underrepresented backgrounds. This finding was race-blind in the experimental context, as voters applied this preference even to white British candidates. Nonetheless, in practice this pattern of voter preferences still poses an obstacle to increasing descriptive representation. In the context of actual candidate recruitment by Britain's largest parties, it is of course women (through the Labour party's all-women shortlists) and/or minorities (through the candidate A-list used by the Conservative party) who benefit from these forms of affirmative action (Dommett 2015). Further, voters might use ethnicity as a cue to make faulty inferences about candidates' backgrounds, as they do about policy positions (Karl et al. 2016). Minority candidates may suffer electoral discrimination because of assumed affirmative action, even if they did not personally benefit from it.

We also found two distinct obstacles to substantive representation of minority voters' preferences and interests. First, we found support for the Substantive Representation Hypothesis: voters directly penalized the substantive representation of refugees' and racial minorities' interests. Candidates who supported the most pro-minority positions on both immigration/refugee admissions and enforcement of race equality law were disadvantaged in our hypothetical election results.

Second, minority candidates-especially those identified as black Caribbeansuffered a conditional ethnic penalty. Candidates who took substantive pro-minority policy positions were penalized more if they were identified as black Caribbean than if they were white British. This represents a Catch-22 for many black British voters: the co-ethnic candidates who are most likely to represent their policy views (and who also provide the advantages of descriptive representation) are less likely to win an election while holding those views. Conditional ethnic penalties also have implications for elite gate-keepers, heightening the incentive to avoid recruiting minority candidates who will represent minority constituents' substantive preferences and interests, while perhaps providing more of an opening to conservative minority candidates (Dancygier 2017).

The results have further implications for understanding the relative positions of Europe's Muslim minorities in comparison with other domestic minority groups. In the British case, Pakistani (Muslim) candidates face outright electoral discrimination in ways that black Caribbean candidates do not. This is consistent with emerging research suggesting that discrimination, lack of integration, and potential for political conflict remain higher with respect to Muslims than for other minority groups across Western Europe (Storm et al. 2017).

Of course, even without categorical discrimination, black Caribbean candidates still face significant roadblocks. Experimental results indicate that black candidates 
must take significant steps to distance themselves from real or perceived implications of their ethnic identities in order to be treated equally by British voters. In our controlled, hypothetical context, black Caribbean candidates could evade negative effects of discrimination on their vote share, but only by refraining from pro-minority policy positions on immigration and law enforcement, and avoiding assumptions that they benefitted from affirmative action. In real elections, this is much more difficult. In real campaigns, voters, often ill-informed about policy matters, may draw the sorts of inferences about black candidates' ideological and policy positions that have been shown to harm minority candidates' chances in US studies. And rejecting substantive pro-minority policies could reduce support from ethnic minority voters and even among the most anti-racist white voters. Nonetheless, these barriers appear more permeable than the categorical discrimination facing Pakistani candidates.

\section{Generalizability}

The principal threat to the generalizability of our results is that they come from an artificial survey experiment environment. This is a limitation of any study of this type; however, in this case we are reassured that our results concur with the observational evidence on ethnic penalties in British elections. But beyond basic questions of external validity, we are also interested in exploring how these results might be applicable - or at least testable — in other national contexts. We expect our results regarding electoral discrimination to be especially relevant in contexts where individual candidates are important-i.e., elections run under single member district plurality rules or proportional representation systems with explicit voting for or against candidates. Indeed, we have noted parallels between our results and studies of anti-Muslim sentiment and political behavior in the US.

However, we also note that the broader questions surrounding the policy representation of minorities and affirmative action can be highly salient issues in elections regardless of the electoral system. The UK's situation in this regard as a multi-ethnic European democracy where ethnic diversity and immigration are highly salient and politicized debates is far from unique, and increasingly European elections are defined by issues of immigration and multiculturalism. Our results support and extend the literature regarding the on-going reorientation of British and European politics around a cosmopolitan-communitarian dimension (Hooghe and Marks 2018), also identified by Jennings and Stoker (2016) as the "cosmopolitan-backwater" geographical values divide, and connected to the politics of the "left behind" or "losers of globalization" (Kriesi et al. 2012).

\section{Pro-minority Voting and the Values Divide}

Despite finding significant levels of ongoing discrimination, our study uncovers some positive signs for supporters of racial and ethnic equality. First, only a small percentage of voters applied these categorical and conditional ethnic penalties 
in their hypothetical voting decisions. Policy variables had substantially larger effects than candidate ethnicity did. This is perhaps cold comfort, since even a small shift in votes can be decisive in a competitive election, and any real or perceived disadvantage faced by minority candidates can be magnified through influence on party elites' gatekeeping at the candidate recruitment stage.

More importantly, we also find evidence of a positive motivation among some white British people to act in a pro-minority manner. Voters with high levels of IMCP (the top quartile) provide a small advantage to minority candidates, suggesting a positive value for descriptive representation or diversity. At the same time, for voters at the other end of this spectrum or even in the middle, minority ethnicity is still a disadvantage. In fact, the aggregate non-effect for black Caribbean candidates gives a misleading picture of neutrality: in truth, black candidates were disadvantaged among voters at lower ends of the IMCP spectrum and at a slight advantage among those at the higher end.

Scholars have used the cosmopolitan-communitarian divide to understand Europeans' views of immigration (Van Der Brug and Van Spanje 2009), EU integration (Hooghe and Marks 2018), and Brexit (Hobolt 2018). We would simply add that analagous disputes over the value of diversity and racial/ethnic equality have broader implications for domestic electoral politics and political integration. British voters are divided on whether descriptive and substantive representation of ethnic minority populations is a positive goal to be pursued, an outcome to be avoided, or an irrelevant consideration. Further, by linking the issue of underrepresentation and electoral discrimination to the broader values divide literature, we reframe the issue of minority representation in a subtle but important way: broadening support for descriptive and substantive representation of minorities depends not only on reducing prejudice, but also on generating affirmative support for diversity and anti-prejudice as positive values.

Funding This project received support from NORFACE ERA-NET (New Opportunities for Research Funding Agency Cooperation in Europe Network) Welfare State Futures Programme, Grant Number 462-14-010.

Open Access This article is licensed under a Creative Commons Attribution 4.0 International License, which permits use, sharing, adaptation, distribution and reproduction in any medium or format, as long as you give appropriate credit to the original author(s) and the source, provide a link to the Creative Commons licence, and indicate if changes were made. The images or other third party material in this article are included in the article's Creative Commons licence, unless indicated otherwise in a credit line to the material. If material is not included in the article's Creative Commons licence and your intended use is not permitted by statutory regulation or exceeds the permitted use, you will need to obtain permission directly from the copyright holder. To view a copy of this licence, visit http://creativecommons.org/licen ses/by/4.0/.

\section{References}

Abrajano, M. A., Elmendorf, C. S., \& Quinn, K. M. (2018). Labels vs. pictures: Treatment-mode effects in experiments about discrimination. Political Analysis, 26, 20-33.

Allport, G. W. (1954). The nature of prejudice. Cambridge, MA: Addison-Welsey. 
Besco, R. (2018). Friendly fire: Electoral discrimination and ethnic minority candidates. Party Politics. https://doi.org/10.1177/1354068818761178.

Blinder, S., \& Richards, L. (2019). UK public opinion toward immigration: overall attitudes and level of concern. Oxford: The Migration Observatory at the University of Oxford.

Blinder, S., Ford, R., \& Ivarsflaten, E. (2013). The better angels of our nature: How the antiprejudice norm affects policy and party preferences in Great Britain and Germany. American Journal of Political Science, 57(4), 841-857.

Bloemraad, I. (2013). Accessing the corridors of power: Puzzles and pathways to understanding minority representation. West European Politics, 36(3), 652-670.

Campbell, R., \& Cowley, P. (2014). What voters want: Reactions to candidate characteristics in a survey experiment. Political Studies, 62(4), 745-765.

Costa, M. (2017). How responsive are political elites? A meta-analysis of experiments on public officials. Journal of Experimental Political Science, 4(3), 241-254.

Cowley, P., \& Kavanagh, D. (2018). The British general election of 2017. Basingstoke: Palgrave Macmillan.

Crenshaw, K. (1989). Demarginalizing the intersection of race and sex: A black feminist critique of antidiscrimination doctrine, feminist theory and antiracist politics. University of Chicago Legal Forum, 1989(1), 139-167.

Dancygier, R. M. (2010). Immigration and conflict in Europe. New York: Cambridge University Press.

Dancygier, R. M. (2017). Dilemmas of inclusion: Muslims in European politics. Princeton: Princeton University Press.

Dancygier, R. M., Lindgren, K. O., Oskarsson, S., \& Vernby, K. (2015). Why are immigrants underrepresented in politics? Evidence from Sweden. American Political Science Review, 109(4), $703-724$.

Dommett, K. (2015). The theory and practice of party modernisation: The conservative party under David Cameron, 2005-2015. British Politics, 10(2), 249-266.

Evans, G., \& Menon, A. (2017). Brexit and British politics. Cambridge: Polity Press.

Fieldhouse, E., Green, J., Evans, G., Schmitt, H., van der Eijk, C., Mellon, J., et al. (2017). British Election Study Internet Panel Waves, pp 1-14. https://doi.org/10.15127/1.293723.

Fisher, S. D., Heath, A. F., Sanders, D., \& Sobolewska, M. (2015). Candidate ethnicity and vote choice in Britain. British Journal of Political Science, 45(4), 883-905.

Ford, R. (2011). Acceptable and unacceptable immigrants: How opposition to immigration in Britain is affected by migrants' region of origin. Journal of Ethnic and Migration Studies, 37(7), 1017-1037.

Fulton, S. A., \& Gershon, S. A. (2018). Too liberal to win? Race and voter perceptions of candidate ideology. American Politics Research, 46(5), 909-939.

Gay, C. (2002). Spirals of trust? The effect of descriptive representation on the relationship between citizens and their government. American Journal of Political Science, 46(4), 717-732.

Gest, J. (2016). The new minority: White working class politics in an age of immigration and inequality. Oxford: Oxford University Press.

Goodwin, M. J. (2011). New British fascism: Rise of the British national party. Abingdon: Routledge.

Haghighat, R. (2007). The development of the brief social desirability scale (BSDS). Europe's Journal of Psychology. https://doi.org/10.5964/ejop.v3i4.417

Hainmueller, J., Hopkins, D. J., \& Yamamoto, T. (2014). Causal inference in conjoint analysis: Understanding multidimensional choices via stated preference experiments. Political Analysis, 22(1), $1-30$.

Heath, A., Fisher, S. D., Rosenblatt, G., Sanders, D., \& Sobolewska, M. (2013). The Political Integration of Ethnic Minorities in Britain. Oxford: Oxford University Press.

Hobolt, S. B. (2018). Brexit and the 2017 UK General Election. Journal of Common Market Studies, 56, 39-50.

Hooghe, L., \& Marks, G. (2018). Cleavage theory meets Europe's crises: Lipset, rokkan, and the transnational cleavage. Journal of European Public Policy, 25(1), 109-135.

Huddy, L. (2018). The group foundations of democratic political behavior. Critical Review, 30(1-2), $1-16$.

Ivarsflaten, E., Blinder, S., \& Ford, R. (2010). The anti-racism norm in Western European immigration politics: Why we need to consider it and how to measure it. Journal of Elections, Public Opinion \& Parties, 20(4), 421-445. 
Jennings, W., \& Stoker, G. (2016). The bifurcation of politics: Two Englands. The Political Quarterly, 87(3), 372-382.

Kalkan, K. O., Layman, G. C., \& Green, J. C. (2018). Will Americans Vote for muslims? cultural outgroup antipathy, candidate religion, and US voting behavior. Politics and Religion, 11(4), 798-829.

Kalkan, K. O., Layman, G. C., \& Uslaner, E. M. (2009). 'Bands of others'? Attitudes toward Muslims in contemporary American Society. Journal of Politics, 71(3), 847-862.

Karl, K. L., Ryan, T. J., Allen, R. B., Ebbesen, E. B., Banducci, S. A., Karp, J. A., et al. (2016). When are stereotypes about black candidates applied? An experimental test. The Journal of Race, Ethnicity, and Politics, 1(02), 253-279.

Kelley, N., Khan, O., \& Sharrock, S. (2017). Racial prejudice in Britain Today. https://natcen.ac.uk/newsmedia/press-releases/2017/september/new-report-uncovers-extent-of-racial-prejudice-in-britain/.

Kriesi, H., Grande, E., \& Dolezal, M. (2012). Political Conflict in Western Europe. Cambridge: Cambridge University Press.

LeVine, R. A., \& Campbell, D. T. (1972). Ethnocentrism: Theories of conflict, ethnic attitudes, and group behavior. New York: Wiley.

Luthra, R., \& Platt, L. (2016). Elite or middling? International students and migrant diversification. Ethnicities, 16(2), 316-344.

Mansbridge, J. (1999). Should blacks represent blacks and women represent women? A contingent 'yes'. The Journal of Politics, 61(3), 628-657.

Martin, N. S. (2015). Do ethnic minority candidates mobilise ethnic minority voters? Evidence from the 2010 UK general election. Parliamentary Affairs, 69, 159-180.

Martin, N. S. (2019). Ethnic minority voters in the UK 2015 general election: A breakthrough for the conservative party? Electoral Studies, 57, 174-185.

Maxwell, R. (2010). Political Participation in France among Non-European-Origin Migrants: Segregation or Integration? Journal of Ethnic and Migration Studies., 36, 425-443.

Merolla, J. L., Sellers, A. H., \& Fowler, D. J. (2013). Descriptive representation, political efficacy, and African Americans in the 2008 presidential election. Political Psychology, 34(6), 863-875.

Messina, A. M. (2007). The logics and politics of post-WWII migration to Western Europe. New York: Cambridge University Press.

Modood, T. (2005). Multicultural politics: Racism, ethnicity, and Muslims in Britain. Edinburgh: Edinburgh University Press.

Moisi, E., Magyar, A., \& Hudson, J. (2017). 2017 candidate selection: More centralised and more representative? The Constitution Unit blog. https://constitution-unit.com/2017/05/09/2017-candidateselection-more-centralised-and-more-representative.

Montgomery, J. M., Nyhan, B., \& Torres, M. (2018). How conditioning on posttreatment variables can ruin your experiment and what to do about it. American Journal of Political Science, 62(3), $760-775$.

Pantoja, A. D., \& Segura, G. M. (2003). Does ethnicity matter? Descriptive representation in legislatures and political alienation among Latinos. Social Science Quarterly, 84(2), 441-460.

Parker, C. S, \& M. A. Barreto. 2014. Change they can't believe. In: The tea party and reactionary politics in America-Updated Edition. Princeton: Princeton University Press.

Plant, E. A., \& Devine, P. G. (1998). Internal and external motivation to respond without prejudice scales. Journal of Personality and Social Psychology, 75, 811.

Portmann, L., \& Stojanović, N. (2018). Electoral discrimination against immigrant-origin candidates. Political Behavior, 41, 105-134.

Rienzo, C. \& Vargas-Silva, C. (2018). Migrants in the UK: An overview-Migration Observatory Briefing. https://migrationobservatory.ox.ac.uk/resources/briefings/migrants-in-the-uk-an-overview/.

Saalfeld, T., \& Bischof, D. (2013). Minority-ethnic MPs and the substantive representation of minority interests in the House of Commons, 2005-2011. Parliamentary Affairs, 66, 305-328.

Sides, J., \& Gross, K. (2013). Stereotypes of Muslims and support for the war on terror. Journal of Politics, 75(3), 583-598.

Sobolewska, M. (2013). Party strategies and the descriptive representation of ethnic minorities: The 2010 British general election. West European Politics, 36(2), 615-633.

Sobolewska, M., McKee, R., \& Campbell, R. (2018). Explaining motivation to represent: How does descriptive representation lead to substantive representation of racial and ethnic minorities? West European Politics, 41, 1237-1261.

Stegmaier, M., Lewis-Beck, M. S., \& Smets, K. (2013). Standing for parliament: Do Black, Asian and minority ethnic candidates pay extra? Parliamentary Affairs, 66(2), 268-285. 
Storm, I., Sobolewska, M., \& Ford, R. (2017). Is ethnic prejudice declining in Britain? Change in social distance attitudes among ethnic majority and minority Britons. British Journal of Sociology, 68(3), $410-434$.

Street, A. (2014). Representation despite discrimination: minority candidates in Germany. Political Research Quarterly, 67(2), 374-385.

Tate, K. (2001). The political representation of Blacks in congress: Does race matter? Legislative Studies Quarterly, 26(4), 623-638.

Thrasher, M., Borisyuk, G., Rallings, C., \& Webber, R. (2017). Candidate ethnic origins and voter preferences: Examining name discrimination in local elections in Britain. British Journal of Political Science, 47(2), 413-435.

Van Der Brug, W., \& Van Spanje, J. (2009). Immigration, Europe and the 'new' cultural dimension. European Journal of Political Research, 48(3), 309-334.

Publisher's Note Springer Nature remains neutral with regard to jurisdictional claims in published maps and institutional affiliations. 